\title{
Audit TI Perusahaan Konsultan Properti Untuk Evaluasi Pengelolaan Data (DS11)
}

\author{
Lala Nilawati \\ AMIK BSI Jakarta \\ e-mail: lala.Ini@bsi.ac.id
}

\begin{abstract}
Abstrak
Teknologi informasi (TI) menjadi bagian penting dalam menentukan keberhasilan perusahaan. TI memberikan kesempatan untuk mendapatkan keunggulan kompetitif dan menawarkan perlengkapan untuk meningkatkan produktifitas. PT Triexpi Properti Advisindo merupakan Perusahaan Konsultan dibidang properti, yang sudah menerapkan penggunaan teknologi informasi untuk pengelolaan data sistem informasi penyewaan properti yang berbasis web. Untuk memaksimal penggunaan teknologi informasi di perusahaan ini, maka akan dibutuhkan kegiatan audit IT. Audit TI yang dilakukan pada penelitian ini akan difokuskan untuk melakukan evaluasi terhadap rancangan database pada sistem informasi penyewaan properti pada PT Triexpi Properti Advisindo. Kegiatan audit TI ini bertujuan untuk evaluasi pengelolaan data pada sistem informasi penyewaan dengan menggunakan Domain Delivery \& Support (DS)-DS11, yang membahas tentang bagaimana mengelola data secara efektif, yaitu dengan melakukan identifikasi kebutuhan data menggunakan kerangka kerja Cobit 4.1. Kemudian akan digunakan model maturity untuk mengontrol proses-proses TI, dengan menggunakan metode penilaian/scoring. Dengan adanya audit pada sistem informasi ini, diharapkan dapat menunjang semua kegiatan perusahaan dan memberikan informasi yang dibutuhkan baik oleh karyawan maupun Direktur dalam menentukan pengambilan keputusan.
\end{abstract}

Kata Kunci: Audit TI, COBIT 4.1., Domain Delivery \& Support (DS) - DS11

\begin{abstract}
Information technology (IT) becomes an important part in determining the success of the company. IT provides an opportunity to gain competitive advantage and offer equipment to increase productivity. PT Triexpi Properti Advisindo is a property consultant company, which has applied the use of information technology for data management of web based property rental information system. To maximize the use of information technology in this company, it will require IT audit activities. IT audit conducted in this research will be focused to evaluate the database design on property information rental system at PT Triexpi Properti Advisindo. This IT audit activity aims to evaluate the management of data on rental information systems using Domain Delivery \& Support (DS) - DS11, which discusses how to effectively manage data by identifying data needs using Cobit 4.1. Then the maturity model will be used to control the IT processes, using the scoring method. With the audit on this information system, is expected to support all the activities of the company and provide information needed both by employees and Directors in determining decision making.
\end{abstract}

Keywords: Audit TI, COBIT 4.1., Domain Delivery \& Support (DS) - DS11.

\section{Pendahuluan}

Pentingnya teknologi informasi (TI) sangat berpengaruh dan dapat mengubah tata cara mengelola bisnis secara signifikan, Dalam pengelolaan $\mathrm{TI}$ harus digunakan secara optimal, efektif, efisien serta tepat sasaran. (Sembiring, Mudjihartono, \& Rahayu, 2013). Teknologi informasi ( $\mathrm{Tl}$ ) menjadi bagian penting dalam menentukan keberhasilan perusahaan, selain itu Teknologi informasi digunakan untuk mendukung perusahaan untuk merespon tekanan bisnis maupun untuk membantu mencapai tujuan dari perusahaan (Indriyani, 2013). PT Triexpi Properti Advisindo merupakan Perusahaan Konsultan dibidang properti. PT Triexpi Properti Advisindo sudah menerapkan penggunaan teknologi informasi, untuk pengelolaan data sistem informasi penyewaan properti yang berbasis web. Namun sistem yang telah ada belum terintegrasi dengan divisi lainnya, yang berhubungan dengan kegiatan perusahaan 
seperti divisi operasional dan divisi marekting dan antar divisi lainnya. Untuk memaksimal penggunaan teknologi informasi di perusahaan ini, maka akan dibutuhkan kegiatan audit IT. Dengan adanya audit pada sistem informasi ini, diharapkan dapat menunjang semua kegiatan perusahaan dan memberikan informasi yang dibutuhkan baik oleh karyawan maupun Direktur dalam menentukan pengambilan keputusan.

Pada penelitian yang berjudul Analisa Penilaian Maturity Tata Kelola TI Berdasarkan Domain DS dan ME Menggunakan COBIT 4.1 (Carolina, 2015), dijelaskan bahwa pengelolaan TI merupakan struktur hubungan dan proses untuk mengarahkan dan mengendalikan perusahaan, dalam mencapai tujuannya, melalui penambahan nilai dengan tetap memperhatikan keseimbangan antara resiko dan manfaat dalam menerapkan $\mathrm{TI}$ dan proses-proses di dalamnya. Pada penelitian ini dilakukan pembuatan model pengelolaan TI menggunakan domain DS \& ME. Pemilihan kedua domain tersebut disesuaikan dengan permasalahan dan kebutuhan dalam melakukan pengelolaan $\mathrm{TI}$, mencakup penyampaian dan dukungan layanan $\mathrm{TI}$, pengawasan pada seluruh kendali dalam memberikan kontribusi terbaiknya pada pencapaian proses bisnis.

Penelitian Ernawati dan Halim Budi Santoso yang berjudul Audit Tata Kelola Sistem Informasi Menggunakan Kerangka Kerja Control Objective For Information And Related Technology (COBIT), dengan objek penelitian ini adalah Sistem informasi keuangan di Universitas Kristen Duta Wacana (UKDW). Penelitian ini dilakukan dengan menggunakan domain DS dan ME. DS menitikberatkan pada area Delivery and Support dan ME berfokus pada masalah Monitor and Evaluation terhadap layanan teknologi informasi (Ernawati \& Santoso, 2016).

Penelitian Andry dengan judul Audit Tata Kelola TI Menggunakan Kerangka Kerja Cobit Pada Domain DS Dan ME di Perusahaan Kreavi Informatika Solusindo disebutkan bahwa Sebuah layanan Software Customized dikatakan baik dan layak apabila sudah memenuhi standard dan adanya tata kelola IT yang baik pula serta dilihat dari keefektifan penggunaan aplikasi dan dilihat dari kepuasan pengguna dari aplikasi. Oleh karena itu, apabila suatu perusahaan ingin aplikasi lebih berkualitas lalu data yang dihasilkannya lebih berkulitas juga, ada satu tahap terakhir yang harus dilakukan, yaitu auditing (Andry, 2016).

Penelitian Darwis dan Yuniarwati yang berjudul Audit Tata Kelola Teknologi Informasi Menggunakan Framework COBIT 4.1 Sebagai Upaya Peningkatan Keamanan Data Pada Dinas Pendidikan Dan Kebudayaan Kabupaten Pesawaran. Penelitian ini menentukan tingkat kematangan tata kelola teknologi informasi pada Dinas Pendidikan dan Kebudayaan Kabupaten Pesawaran, dengan menggunakan Domain Al (Aquire and Implement) dan DS (Delivery and Support) yang memiliki enam proses, yaitu $\mathrm{Al} 2, \mathrm{Al} 3$, DS3, DS5, DS11, dan DS12. Metode penelitian dan tingkat kematangan diambil berdasarkan Maturity Level, dengan tujuan mengetahui pengelolaan tatakelola teknologi informasi dan tingkat kematangan teknologi informasi berdasarkan metode COBIT 4.1 (Darwis \& Yuniarwati, 2016).

$$
\text { Pada penelitian Azizah yang }
$$

berjudul Audit Sistem Informasi Menggunakan Framework COBIT 4.1 Pada E-Learning Unisnu Jepara membahas tentang tata kelola IT pada Sistem Informasi E-Learning. Disebutkan bahwa Keberadaan elearning dalam proses kegiatan mengajar sangat membantu sekali karena disitu dapat berinteraksi aktif antara mahasiswa dan dosen. Akan tetapi keberadaan e-learning ini patut di audit agar keberlanjutan prosesnya bisa berjalan secara efektif. Audit TI yang dilakukan menggunakan standar framework COBIT 4.1 khusus pada domain deliver and support (DS) khusus pada proses DS 3, DS 5, DS 7, DS 9, DS 10, DS 11, DS 13. Hasil tingkat kematangan (maturity level) pada implementasi e-learning UNISNU Jepara khusus pada domain DS berada pada level 4 yang berarti sudah terukur dan terintegrasi antar proses yang berlangsung (Azizah, 2017)

Audit TI yang dilakukan pada penelitian ini akan difokuskan untuk melakukan evaluasi terhadap rancangan database pada sistem informasi penyewaan properti pada PT Triexpi Properti Advisindo. Dalam melakukan evaluasi, dilakukan beberapa langkah, yaitu:

a. Mengidentifikasi rancangan database yang digunakan apakah integritas dan keamanan data terjamin. 
b. Melakukan analisis resiko.

c. Melakukan pemilihan control objective yang akan digunakan untuk menguji keefektifan dari proses TI yang ada.

d. Mendokumentasikan arsitektur yang ada

e. Mendefinisikan proses-proses TI yang akan dikaji.

f. Mendefinisikan komponen TI yang ada. Kegiatan audit $\mathrm{TI}$ ini bertujuan untuk evaluasi pengelolaan data pada sistem informasi penyewaan dengan menggunakan Domain Delivery \& Support (DS) - DS11, yang membahas tentang bagaimana mengelola data secara efektif yaitu dengan melakukan identifikasi kebutuhan data, menggunakan kerangka kerja Cobit 4.1 dan akan digunakan model maturity untuk mengontrol proses-proses TI, dengan menggunakan metode penilaian/scoring. Kegiatan audit $\mathrm{TI}$ tidak akan diidentikkan dengan aktivitas untuk mencari kelemahan-kelemahan atau hal-hal negatif yang nantinya bisa digunakan untuk menjatuhkan pembuat kebijakan. Sebaliknya, perusahaan dapat memaksimalkan penggunaan audit $\mathrm{TI}$ sebagai perangkat untuk memajukan dan meningkatkan nilai guna $\mathrm{TI}$ itu sendiri

Tata Kelola Teknologi Informasi (Audit IT Governance)

Penerapan IT untuk setiap perusahaan harus diselaraskan dengan strategi dan tujuan bisnis perusahaan. Keselarasan antara penerapan IT dengan strategi dan tujuan bisnis perusahaan dapat dicapai melalui tata kelola IT yang baik. (Syamsu, 2015). Tata kelola TI (IT Governance) adalah struktur kebijakan/prosedur dan kumpulan proses yang bertujuan untuk memastikan kesesuaian penerapan TI dengan dukungannya terhadap pencapaian tujuan organisasi, dengan cara mengoptimalkan keuntungan dan kesempatan yang ditawarkan $\mathrm{TI}$, mengendalikan penggunaan sumber daya $\mathrm{TI}$ dan mengelola resikoresiko terkait TI. Betapa pentingnya menganalisis tingkat kematangan Tata Kelola TI, karena merupakan implementasi prosedur pengukuran tingkat kematangan untuk mendapatkan nilai tingkat kematangan kondisi saat ini pada bisnis goal (Bagye, 2016).

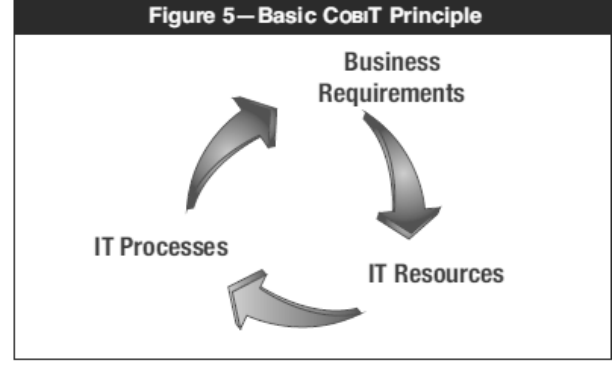

Gambar 1. Framework tata kelola TI Sumber: (IT Governance Institute, 2007)

Pada gambar diatas menggambarkan proses tata kelola yang berawal dengan penentuan obyektif $\mathrm{TI}$ perusahaan, yang memberikan arahan awal, serangkaian aktivitas TI yang dilakukan, kemudian dilakukan pengukuran hasil pengukuran diperbandingkan dengan obyektif, yang akan dapat mempengaruhi arah yang sudah diberikan pada aktivitas $\mathrm{TI}$ dan perubahan obyektif yang diperlukan.

\section{Framework COBIT}

Control Objectives for Information and Related Technology (COBIT), pertama kali diterbitkan pada April 1996. COBIT adalah framework pertama yang diakui secara internasional untuk IT Governance and Control. Versi COBIT 4.1 dirilis pada tahun 2007. COBIT dikembangkan oleh IT Governance Institute (ITGI) bekerjasama dengan ahli dari berbagai bidang industri, akademisi, pemerintah, serta keamanan IT dan kontrol.

Tujuan Penggunaan COBIT dalam mendukung tata kelola TI, akan dapat memberikan sebuah framework dengan tujuan untuk memastikan hal sebagai berikut:

a. TI selaras dengan bisnis

b. TI memungkinkan bisnis dan memaksimalkan benefit

c. Sumberdaya $\mathrm{TI}$ digunakan dengan tanggung jawab

d. Resiko TI dikelola dengan tepat.

Kerangka kerja COBIT dapat dilihat dari aktivitas teknologi informasi yang didefinisikan kedalam model proses yang generik dan dikelompokkan dalam empat domain (Davis \& Schiller..., 2007) yaitu:

1. Perencanaan dan

Pengorganisasian (PO).

Domain ini meliputi taktik dan strategi serta menyangkut masalah pengidentifikasian cara terbaik $\mathrm{TI}$ untuk memberikan kontribusi yang maksimal terhadap pencapaian tujuan bisnis. 
2. Pengadaan dan Implementasi (Al) Domain ini berfokus kepada pemilihan teknologi yang akan digunakan dalam pelaksanaan proses kerja setelah dilakukan perencanaan dan pengorganisasian yang telah ditetapkan. Proses-proses TI pada domain Al adalah:

3. Penyampaian Layanan dan Dukungan (DS)

Domain berhubungan dengan upaya pemenuhan layanan $\mathrm{TI}$ setelah direncanakan dan diimplementasikan seperti pada keamanan sistem, kesinambungan layanan, pelatihan dan pendidikan untuk karyawan dan pengelolaan data yang sedang berjalan. Proses-proses $\mathrm{TI}$ dalam domain DS meliputi:

a. DS1 - menentukan dan mengelola tingkat pelayanan.

b. DS2 - mengelola layanan dari pihak ketiga.

c. DS3 - mengelola kinerja dan kapasitas.

d. DS4 - menjamin layanan yang berkelanjutan.

e. DS5 - menjamin keamanan sistem.

f. DS6 - mengidentifikasi dan mengelola biaya.

g. DS7 - mendidik dan melatih karyawan.

h. DS8 - mengelola resiko pelayanan dan insiden.

i. $\quad$ DS9 - mengelola konfigurasi.

j. $\quad$ DS10 - mengelola masalah.

k. DS11 - mengelola data.

I. DS12 - mengelola lingkungan fisik

m. DS13 - mengelola operasi.

4. Monitor dan Evaluasi (ME).

Domain ini berfokus pada masalah kendali-kendali yang diterapkan dalam perusahaan, pemeriksaan internal dan eksternal.

Model Kematangan utuk pengelolaan dan kontrol pada proses teknologi informasi didasarkan pada rnetode evaluasi organisasi, sehingga dapat mengevaluasi sendiri dari level tidak ada (0) hingga optimis (5). Pendekatan ini diperoleh dari model kematangan dari Software Engineering Institute yang mendefinisikanny untuk kapabilitas pengembangan perangkat lunak.

Model Maturity

COBIT mempunyai model maturity untuk mengontrol proses-proses $\mathrm{TI}$ dengan menggunakan metode penilaian/scoring sehingga organisasi dapat menilai prosesproses TI yang dimilikinya (skala 0 sampai 5). Maturity Models yang ada pada COBIT dapat dilihat pada Tabel 1.2 berikut ini:

Tabel 1. Maturity Models

\begin{tabular}{|c|c|}
\hline Level & Keterangan \\
\hline 0-Tidak & $\begin{array}{l}\text { Sama sekali tidak ada proses yang } \\
\text { dapat dikenali. Perusahaan bahkan } \\
\text { tidak mengenal kalau ada persoalan } \\
\text { yang perlu diperhatikan. }\end{array}$ \\
\hline 1-inisialisasi & $\begin{array}{l}\text { Adanya kejadian yang diketahui dan } \\
\text { dipandang sebagai persoalan yang } \\
\text { perlu ditangani oleh perusahaan. } \\
\text { Belum ada proses standar, } \\
\text { cenderung diselesaikan oleh } \\
\text { perorangan dan per kasus. } \\
\text { Pengelolaan yang dilakukan tidak } \\
\text { terorganisir. }\end{array}$ \\
\hline $\begin{array}{c}2 \text { - dapat } \\
\text { diulang }\end{array}$ & $\begin{array}{l}\text { Proses sudah berkembang, dimana } \\
\text { prosedur yang sama dilakukan oleh } \\
\text { orang yang berbeda. Belum ada } \\
\text { komunikasi atau pelatihan formal } \\
\text { atas prosedur standar, dan } \\
\text { tanggungjawab diserahkan pada } \\
\text { individu. Terdapat kepercayaan } \\
\text { yang tinggi pada kemampuan } \\
\text { individu, sehingga kesalahan } \\
\text { sangat mungkin terjadi. }\end{array}$ \\
\hline 3-ditetapkan & $\begin{array}{l}\text { Prosedur sudah standar dan } \\
\text { terdokumentasi, } \\
\text { dikomunikasikan melalui pelatihan. } \\
\text { Tetapi pelaksanaanya diserahkan } \\
\text { pada individu untuk mengikuti } \\
\text { proses tersebut, sehingga } \\
\text { penyimpangan tidak mungkin akan } \\
\text { diketahui. Prosedurnya belum } \\
\text { sempurna, namun sekedar } \\
\text { formalitas atas praktek yang ada. }\end{array}$ \\
\hline 4-diatur & $\begin{array}{l}\text { Memungkinkan untuk memonitor } \\
\text { dan mengukur kepatuhan terhadap } \\
\text { prosedur, serta mengambil tindakan } \\
\text { atas ketidakefektifan proses yang } \\
\text { terjadi. Proses meningkat secara } \\
\text { konstan dan memberikan praktek } \\
\text { yang baik. Otomasi dan tool } \\
\text { digunakan dengan cara terbatas } \\
\text { dan terpecah-pecah. }\end{array}$ \\
\hline
\end{tabular}

Sumber: : (IT Governance Institute, 2007)

Tabel 2. Maturity Models Lanjutan

\begin{tabular}{|c|l|}
\hline Level & \multicolumn{2}{|c|}{ Keterangan } \\
\hline \multirow{5}{*}{$5-$} & $\begin{array}{l}\text { Proses diperbaiki pada tingkat } \\
\text { praktek terbaik, didasarkan pada } \\
\text { hasil peningkatan berkelanjutan dan } \\
\text { pemodelan maturity dengan } \\
\text { perusahaan lain. TI digunakan } \\
\text { dengan cara terintegrasi untuk } \\
\text { mengotomasi timalisasi } \\
\text { menyediakan tool unflow, } \\
\text { meningkatkan dan } \\
\text { efektifitas, sehingga perusahaan } \\
\text { dapat beradaptasi dengan cepat. }\end{array}$ \\
\hline
\end{tabular}

Sumber: (IT Governance Institute, 2007) 
Tabel 3. Range Maturity Models

\begin{tabular}{|c|c|c|}
\hline No & Range nilai & Level maturity \\
\hline 1 & $0.0-0.49$ & 0 - Tidak ada \\
\hline 2 & $0.50-1.49$ & 1 - Inisiasi \\
\hline 3 & $1.50-2.49$ & 2-Dapat diulang \\
\hline 4 & $2.50-3.49$ & 3- ditetapkan \\
\hline 5 & $3.50-4.49$ & 4 - Diatur \\
\hline 6 & $4.50-5.00$ & 5 -Dioptimalisasi \\
\hline
\end{tabular}

Sumber: : (IT Governance Institute, 2007)

\section{Metode Penelitian}

Pada dasarnya dalam metodologi audit TI ini dilakukan pengumpulan data dan penelaahan rancangan database pada sistem sistem informasi penyewaan properti yang berbasis web yang digunakan oleh perusahaan, yaitu meliputi:

a. Observasi dan wawancara dengan pihak terkait, yaitu bagian operasional, bagian marketing dan bagian teknik infomasi (TI).

b. Melakukan pengecekan apakah tabeltabel database yang telah diinput terjaga integritasnya.

c. Menganalisis aspek-aspek penting dalam rancangan basis data yang digunakan seperti: redudansi data, inkonsistensi data, dan keamanan data.

Untuk metode penarikan sampel yang digunakan dalam penelitian ini adalah teknik purposive sampling, yaitu sampel yang diambil dengan maksud atau tujuan tertentu. Penilitian ini menggunakan instrumentasi dalam bentuk kuesioner. Pernyataan kuesioner dikembangkan berdasarkan jumlah pernyataan atau statement pada tiang tingkat maturity di setiap control objective pada domain Delivery and Support (DS)-DS11, yang membahas tentang bagaimana mengelola data secara efektif yaitu dengan melakukan identifikasi kebutuhan data, menggunakan kerangka kerja Cobit 4.1. Penelitian ini menggunakan teknik analisis data secara kuantitatif dan deskriptif. Analisis Deskriptif digunakan untuk mengetahui bagaimana tata kelola TI di Perusahaan saat ini, agar dapat memberikan solusi untuk perbaikan pelaksanaan tata kelola teknologi informasi. Teknik analisis kuantitatif yaitu dengan menggunakan spreadsheet Microsoft Excel untuk mengolah semua jawaban dan menjelaskan perumusan masalah tingkat kematangan (maturity level) tata kelola
Teknologi Informasi yang dilakukan di perusahaan.

\section{Hasil dan Pembahasan \\ 3.1. Jenis Data}

Jenis data yang digunakan pada penelitian ini adalah Data Primer yaitu data yang langsung diambil ditempat penelitian, seperti wawancara (interview), daftar pertanyaan (questionnaire), dan juga berdasarkan pengamatan terhadap semua hal yang berhubungan dengan pemrosesan pengolahan data, untuk mengetahui permasalahan yang dianalisis. Jumlah responden yang dilibatkan adalah 5 orang.

Responden dan jumlah responden yang dipilih dalam penelitian ini menggunakan metode purposive sampling. Sampel yang dipilih adalah yang memahami Teknologi Informasi di PT Triexpi Properti Advisindo . Dari 5 kuesioner yang dibagikan kepada 5 responden, semuanya kembali (100\%). Data dan jumlah responden dapat dilihat sbb:

Tabel 4. Daftar Responden penelitian

\begin{tabular}{|c|c|c|}
\hline No & Responden & Jumlah \\
\hline 1 & Pimpinan & 1 \\
\hline 2 & Manager Keuangan & 1 \\
\hline 3 & Manager SDM & 1 \\
\hline 4 & Manager IT & 1 \\
\hline 5 & Staff IT & 1 \\
\hline & Jumlah & 5 \\
\hline
\end{tabular}

Sumber: Pengolahan Data Penelitian

(2018)

Selain menggunakan data primer dalam penelitian ini juga menggunakan Data sekunder yang merupakan data yang dikumpulkan secara tidak langsung dari lapangan, seperti:

1. Data gambaran umum perusahaan, seperti sejarah perusahaan, visi dan misi perusahaan dan struktur organisasi.

2. Studi literatur/studi kepustakaan tentang teori dan hal yang berhubungan dengan penelitian.

Dalam penelitian ini hanya mengambil 1 (satu) domain yaitu Domain Penyampaian Layanan dan Dukungan (DS)-DS11 mengenai pengelolaan data. Untuk lebih jelasnya dapat dilihat pada Tabel berikut: 
Tabel 5. Hubungan antara Ruang Lingkup TI dengan Parameter COBIT

\begin{tabular}{|c|c|c|c|c|}
\hline \multirow{2}{*}{$\begin{array}{c}\text { Paramet } \\
\text { er Cobit }\end{array}$} & \multicolumn{4}{|c|}{ Ruang Lingkup TI } \\
\cline { 2 - 5 } & $\begin{array}{c}\text { Aplika } \\
\text { si }\end{array}$ & $\begin{array}{c}\text { Informa } \\
\text { si }\end{array}$ & $\begin{array}{c}\text { Infrastruk } \\
\text { tur }\end{array}$ & $\begin{array}{c}\text { Manus } \\
\text { ia }\end{array}$ \\
\hline $\begin{array}{c}\text { DS11 } \\
\text { (Mengel } \\
\text { ola } \\
\text { Data) }\end{array}$ & $\sqrt{ }$ & $\sqrt{ }$ & $\sqrt{ }$ & - \\
\hline
\end{tabular}

Sumber: Pengolahan Data Penelitian

(2018)

Karena COBIT berorientasi bisnis, maka untuk memahami tujuan kontrol dalam rangka mengelola $\mathrm{TI}$ yang terkait dengan risiko bisnis dilakukan dengan cara:

a. Mulai dengan sasaran bisnis dalam kerangka kerja.

b. Pilih proses dan kontrol TI yang

c. sesuai untuk perusahaan.

d. Operasikan rencana bisnis.

e. Menilai prosedur dan hasil dengan pedoman audit.

\subsection{Kebijakan, Prosedur, Dan Standart PT Triexpi Properti Advisindo}

PT. Triexpi Properti Advisindo telah menetapkan beberapa kebijakan yang sangat dibutuhkan sebagai pedoman/standart dalam melaksanakan setiap kegiatan operationalnya, terlebih lagi

\subsection{Pengujian data}

Pengujian data mengunakan

Domain Penyampaian Layanan dan

Tabel 6. Rekapitulasi Jawaban Responden terhadap Proses Deliver and Support (DS), DS11-Mengelola Data.

\begin{tabular}{|c|c|c|c|c|c|c|c|c|c|}
\hline \multirow{2}{*}{ Domain } & \multirow{2}{*}{ Level } & \multirow{2}{*}{ Pernyataan } & \multicolumn{5}{|c|}{ Jawaban } & \multicolumn{2}{|c|}{ Total Jawaban } \\
\hline & & & R1 & $\mathbf{R} 2$ & R3 & R4 & R5 & Ya & Tidak \\
\hline \multirow{8}{*}{ DS11 } & \multirow{3}{*}{0} & $\mathrm{P} 1$ & $\mathrm{Ya}$ & Tidak & Tidak & Tidak & Tidak & 1 & 4 \\
\hline & & $\mathrm{P} 2$ & $\mathrm{Ya}$ & Tidak & Tidak & Tidak & Tidak & 1 & 4 \\
\hline & & P3 & $\mathrm{Ya}$ & Tidak & Tidak & Tidak & Tidak & 1 & 4 \\
\hline & \multirow{5}{*}{1} & $\mathrm{P} 4$ & $\mathrm{Ya}$ & $\mathrm{Ya}$ & $\mathrm{Ya}$ & $\mathrm{Ya}$ & $\mathrm{Ya}$ & 5 & 0 \\
\hline & & P5 & Tidak & Tidak & $\mathrm{Ya}$ & Ya & $\mathrm{Ya}$ & 3 & 2 \\
\hline & & P6 & Tidak & $\mathrm{Ya}$ & $\mathrm{Ya}$ & $\mathrm{Ya}$ & $\mathrm{Ya}$ & 4 & 1 \\
\hline & & $\mathrm{P} 7$ & $\mathrm{Ya}$ & Tidak & $\mathrm{Ya}$ & $\mathrm{Ya}$ & $\mathrm{Ya}$ & 4 & 1 \\
\hline & & P8 & $\mathrm{Ya}$ & $\mathrm{Ya}$ & $\mathrm{Ya}$ & $\mathrm{Ya}$ & $\mathrm{Ya}$ & 5 & 0 \\
\hline
\end{tabular}

Sumber: Pengolahan Data Penelitian (2018)

Tabel 7. Rekapitulasi Jawaban Responden terhadap Proses Deliver and Support (DS), DS11-Mengelola Data Lanjutan.

\begin{tabular}{|c|c|c|c|c|c|c|c|c|c|}
\hline \multirow{2}{*}{ Domain } & \multirow{2}{*}{ Level } & \multirow{2}{*}{ Pernyataan } & \multicolumn{5}{|c|}{ Jawaban } & \multicolumn{2}{|c|}{ Total Jawaban } \\
\hline & & & R1 & $\mathbf{R} 2$ & R3 & R4 & R5 & Ya & Tidak \\
\hline \multirow{2}{*}{ DS11 } & \multirow{2}{*}{2} & P9 & $\mathrm{Ya}$ & $\mathrm{Ya}$ & $\mathrm{Ya}$ & Ya & Ya & 5 & 0 \\
\hline & & P10 & $\mathrm{Ya}$ & $\mathrm{Ya}$ & $\mathrm{Ya}$ & $\mathrm{Ya}$ & $\mathrm{Ya}$ & 5 & 0 \\
\hline
\end{tabular}

untuk kegiatan yang langsung berhubungan terutama pelayanan terhadap klien,

a. Pembatasan hak akses dalam mengelola web penyewaan properti sesuai job description yang telah diberikan bagi staff IT, marketing, maupun klien.

b. Menjamin keamanan dan kerahasiaan data privasi klien.

c. Menetapkan teknologi yang digunakan untuk menunjang kegiatan operational terutama yang berhubungan dengan akses web penyewaan properti.

d. Menjamin data yang diolah dalam web sudah terintegrasi dengan baik.

Prosedur yang telah ditetapkan PT.

Triexpi Properti Advisindo adalah sebagai

2. Prosedur pengajuan sewa/pemesanan. pemesanan, meliputi pengecekan ketersediaan propeti sesuai pesanan, koordinasikan hasil pesanan properti yang sesuai dengan ketersediaan.

4. Prosedur negoisasi dengan klien dan pengolahan daftar approvement.

Dukungan (DS) - DS11 mengenai pengelolaan data dapat dilihat pada tabel berikut: dengan penggunaan IT dan pihak luar 


\begin{tabular}{|c|c|c|c|c|c|c|c|c|}
\hline & P11 & $\mathrm{Ya}$ & $\mathrm{Ya}$ & $\mathrm{Ya}$ & $\mathrm{Ya}$ & Tidak & 4 & 1 \\
\hline & P12 & Ya & Ya & $\mathrm{Ya}$ & Ya & Ya & 5 & 0 \\
\hline & P13 & Tidak & $\mathrm{Ya}$ & $\mathrm{Ya}$ & $\mathrm{Ya}$ & Ya & 4 & 1 \\
\hline \multirow{8}{*}{3} & P14 & $\mathrm{Ya}$ & Tidak & $\mathrm{Ya}$ & Tidak & Ya & 3 & 2 \\
\hline & P15 & Tidak & $\mathrm{Ya}$ & $\mathrm{Ya}$ & Tidak & $\mathrm{Ya}$ & 3 & 2 \\
\hline & P16 & $\mathrm{Ya}$ & $\mathrm{Ya}$ & $\mathrm{Ya}$ & Tidak & $\mathrm{Ya}$ & 4 & 1 \\
\hline & P17 & Tidak & $\mathrm{Ya}$ & $\mathrm{Ya}$ & Tidak & $\mathrm{Ya}$ & 3 & 2 \\
\hline & P18 & $\mathrm{Ya}$ & $\mathrm{Ya}$ & $\mathrm{Ya}$ & Tidak & $\mathrm{Ya}$ & 4 & 1 \\
\hline & P19 & Tidak & $\mathrm{Ya}$ & $\mathrm{Ya}$ & Tidak & Tidak & 2 & 3 \\
\hline & P20 & $\mathrm{Ya}$ & Tidak & Tidak & Tidak & $\mathrm{Ya}$ & 2 & 3 \\
\hline & $\mathrm{P} 21$ & $\mathrm{Ya}$ & Tidak & Tidak & Tidak & $\mathrm{Ya}$ & 2 & 3 \\
\hline \multirow{6}{*}{4} & P22 & $\mathrm{Ya}$ & $\mathrm{Ya}$ & Tidak & Tidak & $\mathrm{Ya}$ & 3 & 2 \\
\hline & $\mathrm{P} 23$ & $\mathrm{Ya}$ & Tidak & Tidak & Tidak & $\mathrm{Ya}$ & 2 & 3 \\
\hline & P24 & $\mathrm{Ya}$ & $\mathrm{Ya}$ & $\mathrm{Ya}$ & Tidak & $\mathrm{Ya}$ & 4 & 1 \\
\hline & P25 & $\mathrm{Ya}$ & $\mathrm{Ya}$ & Tidak & Tidak & $\mathrm{Ya}$ & 3 & 2 \\
\hline & P26 & $\mathrm{Ya}$ & $\mathrm{Ya}$ & Tidak & Tidak & Tidak & 2 & 3 \\
\hline & P27 & $\mathrm{Ya}$ & Tidak & Tidak & Tidak & $\mathrm{Ya}$ & 2 & 3 \\
\hline & P28 & Tidak & $\mathrm{Ya}$ & Tidak & Tidak & $\mathrm{Ya}$ & 2 & 3 \\
\hline & P39 & Tidak & Tidak & Tidak & Tidak & $\mathrm{Ya}$ & 1 & 4 \\
\hline & P30 & Tidak & $\mathrm{Ya}$ & Tidak & Tidak & $\mathrm{Ya}$ & 2 & 3 \\
\hline 5 & P31 & $\mathrm{Ya}$ & $\mathrm{Ya}$ & Tidak & Tidak & $\mathrm{Ya}$ & 3 & 2 \\
\hline 5 & P32 & $\mathrm{Ya}$ & $\mathrm{Ya}$ & Tidak & Tidak & $\mathrm{Ya}$ & 3 & 2 \\
\hline & P33 & $\mathrm{Ya}$ & $\mathrm{Ya}$ & Tidak & Tidak & Tidak & 2 & 3 \\
\hline & P34 & Tidak & $\mathrm{Ya}$ & Tidak & Tidak & $\mathrm{Ya}$ & 2 & 3 \\
\hline & P35 & $\mathrm{Ya}$ & $\mathrm{Ya}$ & Tidak & Tidak & $\mathrm{Ya}$ & 3 & 2 \\
\hline
\end{tabular}

Sumber: Pengolahan Data Penelitian (2018)

Dari hasil jawaban responden berdasarkan tabel diatas maka akan dibuat Data domain terhadap Proses Deliver and Support (DS),
DS11- Mengelola data seperti yang terlihat pada tabel dibawah ini:

Tabel 8. Data domain terhadap Proses Deliver and Support (DS), DS11-Mengelola data.

\begin{tabular}{|c|c|c|c|c|c|c|c|c|}
\hline Domain & Responden & Level 0 & Level 1 & Level 2 & Level 3 & Level 4 & Level 5 & $\begin{array}{c}\text { Maturity } \\
\text { Level }\end{array}$ \\
\hline \multirow{3}{*}{ DS11 } & R1 & 0,00 & 0,13 & 0,35 & 0,17 & 0,88 & 0,55 & $\mathbf{2 , 0 9}$ \\
\cline { 2 - 9 } & R2 & 0,00 & 0,16 & 0,53 & 0,20 & 0,71 & 1,16 & $\mathbf{2 , 7 6}$ \\
\cline { 2 - 9 } & R3 & 0,00 & 0,34 & 0,69 & 0,39 & 0,23 & 0,00 & $\mathbf{1 , 6 4}$ \\
\cline { 2 - 9 } & R4 & 0,00 & 0,50 & 1,00 & 0,00 & 0,00 & 0,00 & $\mathbf{1 , 5 0}$ \\
\cline { 2 - 9 } & R5 & 0,00 & 0,23 & 0,37 & 0,26 & 0,76 & 1,00 & $\mathbf{2 , 6 1}$ \\
\hline & & & & & & & $\begin{array}{c}\text { Maturity } \\
\text { Level = }\end{array}$ & $\mathbf{2 , 1 2}$ \\
\hline
\end{tabular}

Sumber: Pengolahan Data Penelitian (2018)

\subsection{Analysis dan Evaluasi Data Menggunakan Level Maturity}

Pada domain DS11 - Mengelola data, dapat dilihat pada 5 proses yang diteliti semuanya berada pada level 2 (Initial). Dimana nilai ini menunjukan belum ada kesadaran keamanan yang dilakukan oleh manajemen, tanggung jawab untuk keamanan pengelolahan data tidak dilakukan dan dipahami, belum ada perencanaan keamanan pengelolahan data, dan solusinya dianalisa dengan faktor resiko. Hasil perhitungan maturity rata-rata memiliki nilai 2.12, yang berarti bahwa kinerja mengolah data pada database berada pada kondisi 2 - dapat diulang, artinya proses sudah berkembang, dimana prosedur yang sama dilakukan oleh orang yang berbeda. Belum ada komunikasi atau pelatihan formal atas prosedur standar, dan tanggungjawab diserahkan pada individu. Terdapat kepercayaan yang tinggi pada 
kemampuan individu, sehingga kesalahan sangat mungkin terjadi.

Pada Proses DS11 Manage Data (mengelola data), fokus utama proses DS11 adalah memelihara kelengkapan, keakuratan, ketersediaan, dan perlindungan data. Agar proses DS11 dapat mencapai maturity level 3, maka yang perlu dilakukan adalah sebagai berikut:
a. Menetapkan dan menerapkan prosedur pengarsipan dan penyimpanan data, agar data tetap dapat diakses dan digunakan.

b. Menetapkan dan menerapkan prosedur pemeliharaan inventarisasi media onsite (basis web) dan menjamin integritas dan penggunaannya.

c. Menetapkan dan menerapkan prosedur untuk mencegah akses pada data dan software yang bersifat sensitif atau confidential.

d. Menetapkan dan menerapkan prosedur untuk perbaikan dan backup sistem, dokumentasi, dan data sejalan dengan kebutuhan bisnis dan kelancaran perencanaan, termasuk pengujian backup.

e. Menetapkan dan menerapkan kebutuhan keamanan pada pengoperasian, dan penyimpanan fisik, dan dapat dipertimbangkan penyimpanan offsite atau lokasi lain.

Beberapa indikator yang digunakan untuk mengukur pencapaian proses DS11 adalah:
a. Kepuasan pemakai terhadap ketersediaan data.
b. Presentasi keberhasilan pemulihan data.
c. Jumlah insiden ketika data yang sensitif dapat diperoleh kembali setelah media dimusnahkan.

\section{Kesimpulan}

Berdasarkan analisa dari hasil pengumpulan bukti selama pelaksanaan audit rancangan database pada PT. Triexpi Properti Advisindo, didapat beberapa temuan yang memuat fakta-fakta baik yang telah dilaksanakan dengan baik sesuai standard COBIT, ataupun yang masih perlu diperbaiki lagi. Adapun fakta-fakta yang telah sesuai dengan standard COBIT diantaranya adalah, masih adanya kebijakan dan prosedur sistem informasi yang jelas dan didokumentasikan, distandarisasi, dikomunikasikan dan disosialisasikan, namun dalam pelaksanaannya belum bisa memenuhi sesuai dengan SOP yang dibuat. Selain itu masih adanya pihak yang bertanggung jawab dalam pengelolaan insiden.

Sedangkan temuan audit dari sisi rancangan database yang ada di PT. Triexpi Properti Advisindo, didapat hasil bahwa masih adanya redudansi data pada data owner, karena pada saat input data properti maka data pemilik properti (owner) akan selalu diinput, walaupun data yang sama tersebut sudah ada. Ini membuat tidak efisien waktu dan mnyebabkan inkonsistensi data. Tidak adanya data master tenant/klien/penyewa tersendiri pada database, menyebabkan pada data transaksi penyewaan diinput manual. Adanya anomali data yaitu proses pada basis data yang memberikan efek samping yang tidak diharapkan, misalnya menyebabkan ketidak konsistenan data atau membuat sesuatu data menjadi hilang ketika data lain dihapus.

\section{Referensi}

Andry, J. F. (2016). Audit Tata Kelola Ti Menggunakan Kerangka Kerja Cobit Pada Domain DS Dan ME di Perusahaan Kreavi Informatika Solusindo. Seminar Nasional Teknologi Informasi dan Komunikasi 2016 (Sentika 2016), 5(2), 287-294.

Azizah, N. (2017). Audit Sistem Informasi Menggunakan Framework COBIT 4.1 Pada E-Learning Unisnu Jepara. Jurnal SIMETRIS, 377-382.

Bagye, W. (2016). Analisis Tingkat Kematangan Sistem Informasi Akademik Menggunakan Framework COBIT 4.1 (Studi Kasus: STMIK Lombok). Journal Speed - Sentra Penelitian Engineering dan Edukasi, 8(1), 1-7.

Carolina, I. (2015). Analisa Penilaian Maturity Level Tata Kelola $\mathrm{Ti}$ Berdasarkan Domain Ds Dan Me Menggunakan COBIT 4.1. Seminar Nasional Inovasi dan Tren (SNIT) 2015, 191-196.

Darwis, D., \& Yuniarwati. (2016). Audit Tata Kelola Teknologi Informasi Menggunakan Framework COBIT 4.1 


\begin{tabular}{lcc} 
Sebagai Upaya & \multicolumn{2}{c}{ Peningkatan } \\
Keamanan Data & Pada Dinas \\
Pendidikan & Dan Kebudayaan \\
Kabupaten Pesawaran. Explore - \\
Jurnal Sistem Informasi dan \\
Telematika, 43-49.
\end{tabular}

Davis, C., \& Schiller..., M. (2007). IT auditing: using controls to protect information assets. McGrawHill, 8th.

Ernawati, L., \& Santoso, H. (2016). Audit Tata Kelola Sistem Informasi Menggunakan Kerangka Kerja Control Objective for Information and Related Technology (COBIT). Seminar Nasional Teknologi Informasi dan Multimedia 2016, 6-7.

Indriyani, F. (2013). Perencanaan Tata Kelola Teknologi Informasi Menggunakan Framework Cobit 4.1 (Studi Kasus PT. Netwave Teknologi). Pilar Nusa Mandiri, IX, 38-43.

IT Governance Institute. (2007). Framework Control Objectives Management Guidelines Maturity Models. USA: IT Governance Institute.

Sembiring, S. W., Mudjihartono, P., \& Rahayu, S. (2013). Evaluasi Penerapan Teknologi Informasi di PT. Prudential Indonesia Menggunakan Model Cobit Framework 4.1. Seminar Nasional Informatika 2013 (semnasIF 2013), A-215-A-223.

Syamsu, S. (2015). Evaluasi Tata Kelola Teknologi Informasi Dengan Model Maturity Level Menggunakan Framework COBIT 4.1 (Studi Kasus : PT . Suracojaya Abadi Motor). Journal Speed-Sentra Penelitian Engineering dan Edukasi, 7(4), 35-40. 